\title{
Making an Arranged Marriage Work: A Game-Theoretic Analysis
}

\author{
Amitrajeet A. Batabyal \\ Department of Economics, Rochester Institute of Technology, Rochester, NY, USA \\ Email: aabgsh@rit.edu
}

Received 8 April 2016; accepted 31 May 2016; published 3 June 2016

Copyright (C) 2016 by author and Scientific Research Publishing Inc.

This work is licensed under the Creative Commons Attribution International License (CC BY).

http://creativecommons.org/licenses/by/4.0/

(c) (i) Open Access

\begin{abstract}
In this note, we analyze a simple game model of effort and time investment in an arranged marriage where the goal of the two partners making this investment is to create a better marital relationship. We first specify the best response functions of the two married partners. Next, we solve for the Nash equilibrium and then argue that this equilibrium is unique. Finally, we delineate an interesting connection between the two best response functions in our model and the corresponding best response functions in the well known two-player Cournot game.
\end{abstract}

\section{Keywords}

\section{Arranged Marriage, Effort, Nash Equilibrium, Static Game, Strategic Complements}

\section{Introduction}

Gary Becker [1] was the first researcher to apply modern economic analysis to comprehend the institution of marriage from a theoretical standpoint. Since Becker's seminal work, several economists have studied the subject of marriage from a variety of perspectives. ${ }^{1}$ However, these studies have typically focused on marriages in the western world, that is, on the so-called "love marriages".

Even so, as Levine et al. [6], Kumar and Dhyani [7], and others have pointed out, "arranged marriages” are popular in many nations including, but not limited to, India, Pakistan, and Thailand. An arranged marriage is a marriage in which the two individuals intending to get married do not look for a partner by themselves. Instead, parents, other family members, friends, and even matchmakers look for suitable partners. Even though arranged marriages are common in many parts of the world, the theoretical study of arranged marriages began only with

${ }^{1}$ See Manser and Brown [2], Peters [3], and Cornelius [4] for a more detailed corroboration of this claim. In addition, note that if the process of arranging a marriage is viewed as a matching problem then the von Neumann and Morgenstern notion of stability is potentially relevant. See Greenberg et al. [5] for more details on this last point. 
Batabyal [8]. Since then, additional papers by Batabyal [9] [10], Batabyal and Beladi [11], and Liu [12] have examined a variety of pertinent issues such as the impact of a probabilistic reservation quality level on decision making in arranged marriages, the role of meetings and exposure before an arranged marriage, and the conditions under which one ought to have an arranged as opposed to a love marriage.

The studies mentioned in the preceding paragraph have certainly advanced our understanding of several aspects of arranged marriages. Even so, it is important to emphasize that these studies are all prospective in the sense that they analyze the behavior of agents seeking to have an arranged marriage and not those who are already in an arranged marriage. Put differently, to the best of our knowledge, there are no theoretical studies of the activities of agents who are currently in an arranged marriage. Given this lacuna in the literature, the objective of this note is to analyze the strategic interaction between two married partners who invest effort and time in order to create a better marital relationship or, alternately, to make their arranged marriage work.

Clearly, if a better marital relationship is to be created then all marriages-love or arranged-need investments of effort and time. However, in a love marriage, the married partners generally spend a good amount of time together-dating and possibly even living together-before they get married. In contrast, this is typically not the case for partners wishing to have an arranged marriage. Therefore, the two partners in an arranged marriage are significantly more unfamiliar with each other. As a result, Liu [12], Bentley [13], Barker [14], and Anonymous [15] have all rightly noted that the effort and time investment problem is particularly salient in the case of arranged marriages. This observation explains why we concentrate on the effort and time investment problem in the context of arranged marriages.

The rest of this note is organized as follows. Section 2.1 describes the static game model. Section 2.2 specifies the best response functions of the two married partners. Section 2.3 first solves for the Nash equilibrium and then contends that this equilibrium is unique. Section 2.4 delineates an interesting connection between the two best response functions in our model and the corresponding best response functions in the much studied twoplayer Cournot game. Section 3 concludes and then suggests two ways in which the research in this note might be extended.

\section{Analysis}

\subsection{The Game Model}

Consider two individuals or partners who are together in an arranged marriage. The objective of each partner is to invest effort and time in order to create a better marital relationship. Even though effort and time are, in principle, two distinct notions, in the remainder of this note, we use a single variable to model both these notions. Specifically, in our model, each partner invests $e_{i} \geq 0$ and if both partners invest more then we suppose that both partners are better off. There is typically some element of strategy in the interaction between the two married partners. In addition, it is costly for each partner to invest. To account for these two features of the problem, we suppose that the concave utility function of partner $i$ from investment levels $\left(e_{i}, e_{j}\right)$ is given by

$$
u_{i}\left(e_{i}, e_{j}\right)=\left(\beta+e_{j}\right) e_{i}-e_{i}^{2}
$$

where $\beta>0$ can be thought of as a shift variable. Note that the utility function in Equation (1) tells us that the greater is the investment of effort and time by one partner, the more valuable is effort and time investment by the other partner. Let us now specify the best response functions of the two married partners.

\subsection{The Best Response Functions}

If partner $i$ believes that partner $j$ will select $e_{j}$ then (s) he solves

$$
\max _{e_{i}} u_{i}\left(e_{i}, e_{j}\right)=\left(\beta+e_{j}\right) e_{i}-e_{i}^{2}
$$

The first order necessary condition for an optimum is

$$
\beta+e_{j}-2 e_{i}=0 .
$$

Therefore, partner $i$ 's best response function is given by

$$
e_{i}\left(e_{j}\right)=\frac{\beta+e_{j}}{2}, \forall e_{j} \geq 0
$$


We can now compute the Nash equilibrium (in pure strategies) of the game between the two married partners.

\subsection{The Nash Equilibrium}

Inspecting Equation (4), it is clear that the two best response functions are given by

$$
e_{1}=\frac{\beta+e_{2}}{2}, e_{2}=\frac{\beta+e_{1}}{2} \text {. }
$$

Solving these two best response functions simultaneously for the two unknowns, we get

$$
e_{1}^{*}=e_{2}^{*}=\beta \text {. }
$$

In words, the optimal investment of effort and time by each of the two partners equals the constant shift variable $\beta$. Inspecting Equation (6), it is straightforward to confirm that this Nash equilibrium in pure strategies, is unique. This is because $e_{1}^{*}=e_{2}^{*}=\beta$ is the only point at which the two best response functions given in Equation (5) intersect. Our last task in this note is to point out an interesting link between the two best response functions in Equation (5) and the corresponding best response functions in the much studied two-player Cournot game.

\subsection{A Connection}

In the prominent Cournot game between two quantity setting players (firms)—see, for instance, equation 5.2 in Tadelis ([16], p. 87) — the more that firm 2 produces, the lower is the best response quantity produced by firm 1. Put differently, the best response of firm 1 is decreasing in the quantity choice of firm 2. In game-theoretic parlance, the quantity choices of the two firms are strategic substitutes.

In contrast, in the game that we are analyzing, Equation (5) clearly shows that the effort and time investment of married partner 1 is increasing in the corresponding investment of married partner 2. Once again in gametheoretic language, this means that the investment choices of the two partners are strategic complements. In this sense, the game that we have been analyzing thus far is similar to the Bertrand game in which the two players (firms) select prices optimally. This completes our analysis of the "make an arranged marriage work" game.

\section{Conclusion}

We shall not repeat our basic conclusions from Section 2. Having said this, our main summary point is that in this note, we examined a simple game model of effort and time investment in an arranged marriage where the goal of the two partners making this investment was to create a better marital relationship. The analysis conducted here can be extended in a variety of ways. Here are two possible extensions. First, it would be useful to study a dynamic game model in which the two partners are interested not only in creating a better marital relationship but also in maintaining this relationship over time so as to potentially avoid a negative outcome like a divorce. Second, it would also be instructive to study scenarios in which the utility functions of the two partners depend not only on personal choice variables but also on variables that reflect the wishes of near and dear family members. Studies that examine these aspects of the problem will shed valuable additional light on the working of arranged marriages.

\section{References}

[1] Becker, G.S. (1973) A Theory of Marriage: Part I. Journal of Political Economy, 81, 813-846. http://dx.doi.org/10.1086/260084

[2] Manser, M. and Brown, M. (1980) Marriage and Household Decision-Making: A Bargaining Analysis. International Economic Review, 21, 31-44. http://dx.doi.org/10.2307/2526238

[3] Peters, H.E. (1986) Marriage and Divorce: Informational Constraints and Private Contracting, American Economic Review, 76, 437-454.

[4] Cornelius, T.J. (2003) A Search Model of Marriage and Divorce. Review of Economic Dynamics, 6, 135-155. http://dx.doi.org/10.1016/S1094-2025(02)00012-1

[5] Greenberg, J., Luo, X., Oladi, R. and Shitovitz, B. (2002) (Sophisticated) Stable Sets in Exchange Economies. Games and Economic Behavior, 39, 54-70. http://dx.doi.org/10.1006/game.2001.0890 
[6] Levine, R., Sato, S., Hashimoto, T. and Verma, J. (1995) Love and Marriage in Eleven Cultures. Journal of CrossCultural Psychology, 26, 554-571. http://dx.doi.org/10.1177/0022022195265007

[7] Kumar, P. and Dhyani, J. (1996) Marital Adjustment: A Study of Some Related Factors. Indian Journal of Clinical Psychology, 23, 112-116.

[8] Batabyal, A.A. (1998) Aspects of Arranged Marriages and the Theory of Markov Decision Processes. Theory and Decision, 45, 241-253. http://dx.doi.org/10.1023/A:1004998730922

[9] Batabyal, A.A. (2003) On Decision Making in Arranged Marriages with a Stochastic Reservation Quality Level. Applied Mathematics Letters, 16, 933-937. http://dx.doi.org/10.1016/S0893-9659(03)90019-X

[10] Batabyal, A.A. (2004) Meetings and Exposure before an Arranged Marriage: A Probabilistic Analysis. Applied Economics Letters, 11, 473-476. http://dx.doi.org/10.1080/1350485042000244495

[11] Batabyal, A.A. and Beladi, H. (2002) Arranged or Love Marriage? That Is the Question. Applied Economics Letters, 9, 893-897. http://dx.doi.org/10.1080/13504850210161959

[12] Liu, X. (2007) Optimal Dynamic Path of Effort on Marriage: Differences between Arranged and Love Marriages. Applied Economics Letters, 14, 49-52. http://dx.doi.org/10.1080/13504850210161959

[13] Bentley, P. (2011) Why an Arranged Marriage Is More Likely to Develop into Lasting Love. Daily Mail, March 4.

[14] Barker, E. (2014) The Science of 'Happily Ever After’: 3 Things That Keep Love Alive. Time, April 16.

[15] Anonymous (2015) How to Make Your Arranged Marriage Work. Times of India, August 6.

[16] Tadelis, S. (2013) Game Theory. Princeton University Press, Princeton, New Jersey. 